kiểm soát bệnh đáng kể. Cụ thể là:

- 63,7\% bệnh nhân kiểm soát được các triệu chứng cơ năng.

- Đánh giá đáp ứng theo RECIST, tỉ lê kiểm soát được bệnh chiếm $67,4 \%$ trong đó $5,5 \%$ đáp ứng hoàn toàn, $27,3 \%$ đáp ứng một phần, 34,6\% bênh nhân đạt bênh ổn định

- Tác dụng phụ trên hệ tạo huyết: Giảm hồng cầuđộ 4 chỉ chiếm 1,3\%. Giảm bạch cầu trung tính độ 4 là 5,9\%. Độc tính trên gan, thận ít gặp, chủ yếu là độ 1 và độ 2 .

\section{TÀl LIỆ THAM KHẢO}

1. Trần Đình Thơ và CS (2005), Một số đặc điểm dịch tể học của ung thư đường mật, $Y$ học Việt Nam. tháng 5, tâp 310, tr.120-126.

2. Nguyễn Quang Nghĩa, Đoàn Thanh Tùng, Nguyễn Tiến Quyết, (2004), Chẩn đoán và kết quả điêu trị phẫu thuật ung thư đường mật trong gan, Y hoc Viêt Nam. 304, tr.149-159.

3. Đoàn Thanh Tùng, Nguyền Quang Nghĩa, Nguyễn Tiến Quyêt (2005), Nghiên cứu các yếu tố ảnh hưởng đến thời gian sống sau phẫu thuật bênh nhân ung thư đường mật trong gan, $Y$ học Viêtt Nam Số đặc biêtt tháng 5, tr.110-119.

4. Nguyển Tiến Quyêt (2005), Kết quả điều trị ung thư đường mật ngoài gan, Tạp chí Y Học Việt Nam. 310, tr.5.

5. Nguyển Thị Bích Phương, "Đánh giá kết quả điêu trị hóa chất bênh nhân ung thư đường mât không còn khả năng phẫu thuật", luận vằn tốt nghiếp bác sỹ nội trú chuyên ngành ung thư 2015

6. T. Okusaka et al (2010), Gemcitabine alone or in combination with cisplatin in patients with biliary tract cancer: a comparative multicentre study in Japan, Br J Cancer. 103(4), tr. 469-74.

7. J.Dierks et al (2017), Effective treatment of advanced biliary tract carcinoma using 5fluorouracil continuous infusion with cisplatin, Ann Oncol. 9(6), tr. 653

8. J. W. Valle et al (2009), Gemcitabine alone or in combination with cisplatin in patients with advanced or metastatic cholangiocarcinomas or other biliary tract tumours: a multicentre randomised phase II study - The UK ABC-01 Study, Br J Cancer. 101(4), tr. 621-7.

\title{
ĐÁNH GIÁ KẾT QUẢ HÓA TRI BỔ TRỢ PHÁC ĐỒ FOLFOX4 TRONG ĐIỀU TRI UNG THƯ ĐẠI TRÀNG TẠI BỆNH VIỆN THANH NHÀN
}

\section{TÓM TẮT}

Mục tiêu: Đánh giá kết quả và tác dụng không mong muốn của phác đồ FOLFOX4 trong điều trị bổ trơ ung thư đại tràng (UTĐT) tai bệnh viện Thanh Nhàn. Đối tượng và phương pháp nghiên cứu: Mô tả hồi cứu trển 43 bệnh nhân UTĐT đã được phẫu thuât triêt căn, xếp giai đoạn II nguy cơ cao và giai đoạn III được hóa trị bổ trơ phác đồ FOLFOX4 tại bệnh viện Thanh Nhàn từ tháng $1 / 2015$ đến tháng 12/2018. Kết quả: Tỷ lệ sống thêm không bệnh 3 năm là $79,1 \%$, tỷ lệ sông thêm toàn bộ là $88,4 \%$. Tác dụng không mong muốn thường ở mức độ $1-2$, chỉ $14,0 \%$ đôc tính ở đô 3-4, tác dung phu có thể kiểm soát được. Kết luận: Phác đồ FOLFOX4 có hiệu quả điều trị cao và độc tính có thể kiểm soát được trong điều trị bổ trợ UTĐT.

Tư khóa: FOLFOX4, đại tràng, hiệu quả và an toàn

\section{SUMMARY}

\section{EVALUATION OF THE RESULTS OF ADJUVANT CHEMOTHERAPY WITH FOLFOX4 REGIMEN IN COLON CANCER}

\footnotetext{
${ }^{1}$ Bệnh viện Thanh Nhàn

ª̂̀nh viền $K$

Chịu trách nhiệm chính: Bùi Thị Phương Thu

Email: Thuphuongbui.tb@gmail.com

Ngày nhận bài: 21.6.2021

Ngày phản biên khoa hoc: 17.8.2021

Ngày duyệt bài: 23.8.2021
}

\section{Bùi Thị Phương Thu ${ }^{1}$, Đỗ Huyền Nga ${ }^{2}$}

\section{AT THANH NHAN HOSPITAL}

Objectives:To evaluate the results and the sideeffects of the FOLFOX4 regimen in adjuvant treatment of the colon cancer at Thanh Nhan hospital.Objects and methods: Retrospective description of 43 adenocarcinoma colorectal cancer patients were treated with FOLFOX4 regimen at Thanh Nhan hospital from January2015 to December 2018. Results:the 3years disease-free survival (DFS) was $79,1 \%$, the overall survival (OS) was $88,4 \%$. The side-effects were general at thegrade of $1-2$, while there was only $14,0 \%$ at the grade of $3-4$. The side-effects were manageable. Conclusion:The FOLFOX4 regimen in adjuvant chemotherapy was highly effective in the colon cancer treatment. The side-effects were manageable during the treatment process using FOLFOX regimen.

Key word. FOLFOX4, colorectal, efficacy and safety.

\section{I. Đă̆T VẤN ĐỀ}

Ung thư đại tràng (UTĐT) là một bệnh hay gặp ở các nước phát triển, và đang có xu hướng tăng lên ở các nước đang phát triển. Tại Việt Nam ước tính năm 2020 trên cả nước có khoảng 6.448 người mới mắc đứng hàng thứ 5 ở cả hai giới, trong đó tỷ lệ mắc của nam đứng thứ 4 và nữ đứng hàng thứ $3^{1}$. Trên thế giới, nhiều nghiên cứu và thử nghiêm lâm sàng chứng minh được lợi ích của hóa trị bổ trợ sau phẫu thuật đối với UTĐT giai đoạn II nguy cơ cao và giai đoạn 
III. Thử nghiệm lâm sàng MOSAIC, so sánh hóa trị bổ trợ phác đồ FOLFOX với phác đồ FUFA trên bệnh nhân ung thư đại tràng giai đoạn II nguy cơ cao và giai đoạn III, kết quả sống thêm không bênh 3 năm là $78,2 \%$ (FOLFOX)và $72,9 \%$ (FUFA), $p=0,002^{2}$. Tại bệnh viện Thanh Nhàn đã tiến hành điều trị hóa trị bổ trợ phác đồ FOLFOX4 cho bệnh UTĐT từ năm 2015, đã cải thiện thời gian sống thêm không bênh cũng như thời gian sống thêm toàn bộ. Chúng tôi tiến hành nghiên cứu điều trị hóa trị bổ trợ phác đồ FOLFOX4 cho UTĐT sau phẫu thuật với mục tiêu nghiên cứu: Đánh giá kết quả và tác dụng không mong muốn của phác đồ FOLFOX4 trong điều trị bổ trợ UTDT giai đoạn II nguy cơ cao và giai đoan III.

\section{II. ĐỐI TƯợNG VÀ PHƯƠNG PHÁP NGHIÊN CỨU}

Nghiên cứu được tiến hành trên 43 bệnh nhân UTĐT giai đoạn II nguy cơ cao và giai đoạn III được hóa tri tai bênh viên Thanh Nhàn từ tháng 1/2015 đến tháng 12/2018.

\section{Tiêu chuân lưa chon}

- BN chẩn đoán UTĐT giai đoạn II nguy cơ cao và giai đoạn III theo UJCC (2018)

Bệnh nhân UTĐT giai đoạn II nguy cơ cao có một trong các yếu tố: (1) Ung thư biểu mô kém biệt hóa; (2) Có biến chứng do u như tắc ruột hoặc thủng ruột; (3) U T4; (4) U xâm lấn mạch lympho, mạch máu trên vi thể; (5) Số lượng hạch lấy được để làm mô bệnh học ít hơn 12 hạch.

- Điều trị hóa chất bổ trợ với phác đồ FOLFOX4, ít nhất 8 chu kì.

- Điểm toàn trạng PS = 0-1.

- Chức năng gan thận, huyết học trong giới hạn cho phép để điều trị hóa chất.

- Có hồ sơ lưu trữ đầy đủ.

- Theo dõi sau điều trị đến khi bệnh nhân tử vong hoặc hết thời hạn nghiên cứu.

\section{Tiêu chuân loai trừ}

- Không phù hợp các tiêu chuẩn trên.

- Đang mắc bệnh phối hợp nặng: bệnh tim mạch, rối loạn tâm thần, ung thư khác đang tiển triển.

- Mắc bệnh ung thư khác trước đó.

- Bệnh nhân bỏ điều trị không phải vì lý do chuyên môn.

\section{Phương pháp nghiên cứu}

- Phương pháp nghiên cứu: Mô tả hồi cứu

Các bước tiến hành:

- Lập bảng thu thập số liệu.

- Tiến hành chọn bệnh nhân: theo tiêu chuẩn lựa chọn.

- Thu thâp thông tin: tuổi, giới, chỉ số toàn trạng, đặc điểm giải phẫu bệnh khối u.
- Điều trị: hóa trị bổ trợ phác đồ FOLFOX4

Oxaliplatin $85 \mathrm{mg} / \mathrm{m}^{2}$ truyền tĩnh mạch với Glucose $5 \%$ ngày 1.

Levocovorin $200 \mathrm{mg} / \mathrm{m}^{2}$ truyền tĩnh mạch với Glucose $5 \% / \mathrm{NaCl} 0,9 \%$ ngày 1,2 .

$5 F U 400 \mathrm{mg} / \mathrm{m}^{2}$ truyền tĩnh mạch trong $2 \mathrm{~h}$ với Glucose $5 \% / \mathrm{NaCl} 0,9 \%$ ngày 1,2 .

$5 \mathrm{FU} 600 \mathrm{mg} / \mathrm{m}^{2}$ truyền tĩnh mạch trong $22 \mathrm{~h}$ với Glucose $5 \% / \mathrm{NaCl} 0,9 \%$ ngày 1,2 .

Chu kỳ 14 ngày x 12 chu kỳ. Ghi nhân các tác dụng không mong muốn.Hoàn thànhtối thiểu 8 chu kì, theo dõi tái khám định kỳ tai phòng khám của bệnh viện mỗi 3 tháng trong 2 năm đầu.

Đánh giá kết quả điêu trị: Tái phát, tỷ lệ sống thêm không bệnh 3 năm, sống thêm toàn bộ, các tác dụng không mong muốn.

\section{KẾT QUẢ NGHIÊN CỨU}

\subsection{Kết quả điêu tri}

Bảng 3. Kết quả điều trị

\begin{tabular}{|c|c|c|}
\hline & $\begin{array}{c}\text { Bê̂nh } \\
\text { nhân }\end{array}$ & Tỉ lệ \\
\hline Kết quả điều trị & $(\mathrm{n}=43)$ & $100 \%$ \\
\hline Sống không bệnh & 34 & 79,1 \\
\hline Sống có bệnh & 4 & 9,3 \\
\hline Tứ vong & 5 & 11,6 \\
\hline Tái phát, di căn đâu tiên & $(\mathrm{n}=9)$ & $20,9 \%$ \\
\hline Gan & 5 & 55,6 \\
\hline Phối & 2 & 22,2 \\
\hline O bụng & 1 & 11,1 \\
\hline Vết mố & 1 & 11,1 \\
\hline
\end{tabular}

Nhân xét: Thời điếm kết thúc nghiêm cứu ghi nhẩn 5 trường hợp tử vong do tái phát, vị trí tái phát đầu tiên gặp cao nhất là gan chiếm $55.6 \%$.

Bảng 4. Phân bố tỉ lệ và thời gian sống thêm theo tháng

\begin{tabular}{|c|c|c|c|}
\hline Kết quả & $\mathbf{n}$ & Tỉ lệ & $\begin{array}{c}\text { TB } \\
\text { (tháng) }\end{array}$ \\
\hline $\begin{array}{c}\text { Sống thêm không } \\
\text { bệnh 3 năm }\end{array}$ & 34 & 79,1 & $66,1 \pm 3,6$ \\
\hline Sống thêm toàn bộ & 38 & 88,4 & $71,9 \pm 2,9$ \\
\hline
\end{tabular}

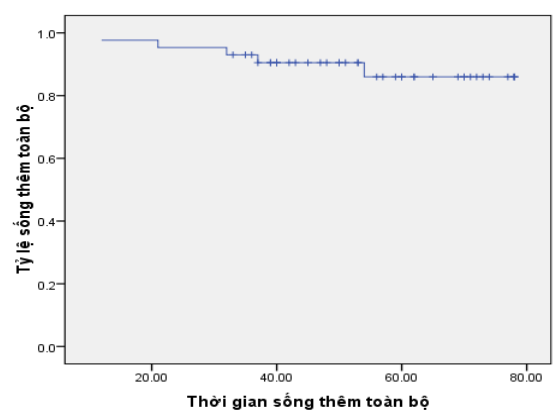

Biểu đồ 1. Thời gian sống thêm toàn bộ 


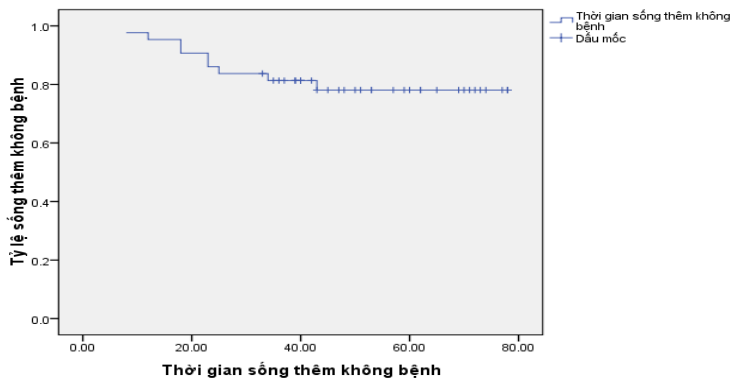

Biểu đồ 2. Thời gian sống thêm không bệnh 3.2 Độc tính hóa trị

Bảng 5. Độc tính trên hệ tiêu hóa, thần kinh, da niêm mạc

\begin{tabular}{|c|c|c|c|}
\hline $\begin{array}{c}\text { Độc tính } \\
\text { (n=43) }\end{array}$ & Độ 1-2 & Độ 3-4 & Tổng \\
\hline Buồn nôn, nôn & $27(62,8 \%)$ & $2(4,7 \%)$ & $29(67.5 \%)$ \\
\hline İa cháy & $1(2,3 \%)$ & 0 & $1(2,3 \%)$ \\
\hline Viêm loét miệng & $2(4,7 \%)$ & 0 & $2(4,7 \%)$ \\
\hline Đau thượng vị & $1(2,3 \%)$ & 0 & $1(2,3 \%)$ \\
\hline Viêm TK ngoại vi & $10(23,2 \%)$ & 0 & $10(23,2 \%)$ \\
\hline $\begin{array}{c}\text { Hội chứng tay, } \\
\text { chân }\end{array}$ & $\begin{array}{c}11 \\
(25,6 \%)\end{array}$ & 0 & $\begin{array}{c}11 \\
(25,6 \%)\end{array}$ \\
\hline
\end{tabular}

Nhận xét: Độc tính trên hệ tiêu hóa, thần kinh, da niêm mạc chủ yếu ở độ $1-2 ; 4,7 \%$ bệnh nhân có độc tính ở độ 3-4. thận

Bảng 6. Độc tính trên hệ tạo huyết, gan,

\begin{tabular}{|c|c|c|c|}
\hline Độc tính & Độ 1-2 & Độ 3-4 & Tống \\
\hline $\begin{array}{c}\text { Giảm bạch cầu } \\
\text { hạt }\end{array}$ & $\begin{array}{c}18 \\
(41,9 \%)\end{array}$ & $\begin{array}{c}4 \\
(9,3 \%)\end{array}$ & $\begin{array}{c}22 \\
(51.2 \%)\end{array}$ \\
\hline $\begin{array}{c}\text { Giảm bạch cầu } \\
\text { có sốt }\end{array}$ & $\begin{array}{c}2 \\
(4,7 \%)\end{array}$ & 0 & $\begin{array}{c}2 \\
(4,7 \%)\end{array}$ \\
\hline $\begin{array}{c}\text { Giảm huyết sắc } \\
\text { tố }\end{array}$ & $\begin{array}{c}9 \\
(20,9 \%)\end{array}$ & 0 & $\begin{array}{c}9 \\
(20,9 \%)\end{array}$ \\
\hline Giảm tiếu cầu & $10(23,3 \%)$ & 0 & $10(23,3 \%)$ \\
\hline $\begin{array}{c}\text { Tăng } \\
\text { SGOT/SGPT }\end{array}$ & $13(30,2 \%)$ & 0 & $\begin{array}{c}13 \\
(30,2 \%)\end{array}$ \\
\hline $\begin{array}{c}\text { Tăng Ure/ } \\
\text { Creatinin }\end{array}$ & $\begin{array}{c}1 \\
(2,3 \%)\end{array}$ & 0 & $\begin{array}{c}1 \\
(2,3 \%)\end{array}$ \\
\hline
\end{tabular}

Nhận xét: Độc tính trên hệ tạo huyết chủ yếu ở độ 1-2, độ 3-4 chỉ có 9,3\%. Độc tính trên gan thận chủ yếu ở độ 1-2; không gặp độ 3-4.

\section{BÀN LUÂ̂N}

Số lượng bệnh nhân nghiên cứu là 43 bệnh nhân. Thời gian nghiên cứu trung bình là 53,3 tháng. Thời gian theo dõi trung bình của 1 số nghiên cứu như của tác giả Andre T. là 37,9 tháng ${ }^{2}$, tác giả Võ Văn Kha (2016) là 40,6 tháng ${ }^{3}$, tác giả Từ Thị Thanh Hương (2019) là 59,2 tháng ${ }^{4}$. Tỷ lệ và thời gian theo dõi của chúng tôi đủ để đánh giá kết quả điều trị.Trong nghiên cứu số bệnh nhân còn sống không bệnh là 34 chiếm 79,1\%, 3 trường hợp tái phát di căn chiếm 9,3\%, 5 trường hợp tử vong chiếm $11,6 \%$. Trong số bệnh nhân tái phát, di căn thì vị trí xuất hiện đầu tiên gặp nhiêu nhất là gan chiếm 55,6\%. Theo Andre T. tỷ lệ tái phát, di căn của UTĐT giai đoạn II nguy cơ cao và III sau hóa trị phác đồ FOLFOX là $21,1 \%$, phác đồ FUFA là $26,1 \%^{2}$. Tác giả Từ Thị Thanh Hương nghiên cứu bệnh nhân UTĐT giai đoan III điều trị bổ trợ phác đồ FOLFOX tỷ lệ tái phát di căn là $26,4 \%$, trong đó di căn gan chiến đa số 39,3\% ${ }^{4}$ cao hơn trong nghiên cứu của chúng tôi có thể là do nhóm bệnh nhân nghiên cứu của tác giả tập trung ở giai đoạn III khối u có sự xâm lấn sâu và di căn hạch nhiều hơn. Gan là vị trí di căn thường gắp nhất. Phần lớn các tế bào ung thư theo tînh mạch cửa về gan, các tế bào ung thư sẽ bị giữ lại tại gan, còn số ít tế bào đến nơi khác.

Thời gian sống them. Nghiên cứu hóa trị bổ trơ, một trong những tiêu chí quan trong nhất để đánh giá hiệu quả của phác đồ là kết quả về thời gian sống thêm không bệnh và toàn bộ sau điều trị. Trong nghiên cứu của chúng tôi tỷ lệ sống thêm 3 năm không bệnh là $79,1 \%$, có 4 bệnh nhân tái phát tại thời điểm theo dõi tháng, thời gian sống thêm không bệnh trung bình đạt 66,1 tháng, tỷ lệ sống thêm toàn bộ 3 năm là $88,4 \%$, có 5 bệnh nhân tử vong tại thời điểm theo dõi, thời gian sống thêm toàn bộ trung bình là 71,9 tháng. Andre T. (2004) nghiên cứu 2,246 bệnh nhân UTĐT đã được phẫu thuật giai đoạn II, III điều trị phác đồ FOLFOX4 và nhóm điêu trị phác đồ FU/FA. Kết quả theo dõi 37,9 tháng, tỷ lệ STKB 3 năm ở phác đồ FOLFOX 4 là $78,2 \%$ và FU/FA là $72,9 \%(p=0,002)$. Tỷ lệ STTB 3 năm ở phác đồ FOLFOX 4 là $87,7 \%$ FU/FA là $86,6 \%$ $(p>0,05)^{2}$. Nghiên cứu Tsai YJ (2016) nghiên cứu 213 bệnh nhân UTĐT giai đoạn III đã phẫu thuật triệt căn điều trị hóa chất bổ trợ phác đồ FOLFOX từ 7 đến 12 chu kỳ hóa chất; kết quả sống 5 năm STTB là $77,9 \%$ và 3 năm STKB là $76,7 \%$ với $p=0,04$ và $p=0,048^{5}$. Tác giả Từ Thi Thanh Hương (2019) nghiên cứu trên 106 bệnh nhân UTĐT giai đoạn III điều trị bổ trợ phác đồ FOLFOX4, thời gian sống thêm 5 năm toàn bộ là $74,5 \%$, sống thêm 3 năm không bệnh đạt $73,6 \%{ }^{4}$. Tác giả Nguyễn Quang Thái (2002) nghiên cứu trên 203 bệnh nhân UTĐT được phẫu thuật giai đoạn 1992-1997 tại bệnh viện K,không điêu trị bổ trợ, sống thêm 5 năm toàn bộ cho các giai đoạn là $46,16 \%$, sống thêm 5 năm toàn bộ cho nhóm bệnh nhân giai đoạn Duke $B$ và Duke C là $53,28 \%$. Điều này thể hiên vai trò quan trọng của hóa trị bổ trợ sau phẫu thuật giúp cải thiện thời gian STKB cũng như STTB ở bệnh 
nhân UTĐT giai đoạn II-III ${ }^{6}$.

Độc tính và các tác dụng không mong muốn là một phần đánh giá về kết quả điều trị của phác đồ. Chúng tôi ghi nhận các độc tính thường ở độ 1-2, chỉ có 9,3\% bệnh nhân bị độc tính ở mức độ 3-4. Không ghi nhận trường hợp nào tử vong do độc tính của hóa tri.

Độc tính lên hệ tiêu hóa, thân kinh, da niêm mạc. Tỉ lệ nổn, buồn nôn thường gặp ở độ 1-2 chiếm 62,8\% ít làm ảnh hưởng đến bệnh nhân, độ 3-4 chiếm 4.7\%. Với các phác đồ chống nồn hiện nay tình trạng này thường được kiểm soát tốt. Chúng tôi thường sử dụng thuốc chống nôn thế hệ 2 ondanstron $8 \mathrm{mg}$,một số trường hợp bệnh nhân cần điều trị thuốc chống nôn thế hệ 3 như palonosetron kết hợp với corticoid. İa chảy gặp 2,3\% chủ yếu ở độ 1 , thường do 5 FU truyền tînh mạch nhanh gây ra. Bệnh nhân khi được xác định ỉa chảy do hóa trị được điều trị với loperamid $4 \mathrm{mg}$ thường có đáp ứng điều trị ngay. Không có trường hợp bệnh nhân nào phải ngừng điêu trị do độc tính ỉa chảy. Viêm loét miệng chỉ gặp 4,7\% ở độ 1-2, bệnh nhân chỉ xuất hiện viêm niêm mạc nhe, loét miệng chiếm tỉ lệ thấp. Đau thượng vị là triệu chứng gây viêm niêm mạc dạ dày, chiếm tỉ lệ thấp chỉ có $2,3 \%$. Các bệnh nhần thường gặp tác dụng không mong muốn trên hệ thần kinh ngoại vi như tê bì, cảm giác kim châm và đau vùng đâu chi. Tỉ lệ độc tính thần kinh ngoại vi là $23,2 \%$ ở độ 1-2. Độc tính này thường gặp sau 45 đợt điều trị do mang tính tích lũy và có thể hồi phục sau $12-18$ tháng. Hội chứng bàn tay bàn chẩn gặp $25,6 \%$ bệnh nhẩn chỉ gặp ở độ $1-2$, bệnh nhân cảm giác khó chịu tăng dần ở các chu kì sau, giảm dần khi kết thúc điều trị và không có bênh nhân nào găp tác dụng phụ ở độ 3-4.

Đốc tính trên hệ tạo huyết, gan và thận. Độc tính trên hệ tạo huyết thường gặp nhất là hạ bạch cầu hạt chiếm tỉ lệ 41,9\%, trong đó 9,3\% giảm độ 3-4. Phần lớn những bệnh nhân giảm độ $1-2$ sau nghỉ 1 tuần tự hồi phục lại tiếp túc điều trị, những bệnh nhân hạ độ 3-4 thường dùng thuốc kích thích tạo bach cầu Filgrastim 1-2 ngày bạch cầu sẽ tăng trở lại.Trongnghiên cứu hạ bạch cầu có sốt chiếm $1,6 \%$, phải dùng thuốc kích thích tăng bạch câu và kháng sinh phổ rộng truyền tĩnh mạch từ 5-7 ngày. Hạ tiểu cầu cũng là độc tính trền hệ tạo huyết thường gặp chiếm $23,3 \%$ chỉ gặp ở độ 1-2, đều tự hồi phục. Oxaliplatin là nguyên nhân gây hạ tiểu cầu trong quá trình điều trị. Giảm huyết sắc tố độ 1-2 gặp $19,2 \%$, thông thường bệnh nhân tự hồi phục. Độc tính ngoài hệ tạo huyết thường gặp được ghi nhận là độc tính gan với biểu hiện tăng men gan gặp $30.2 \%$ và độc tính thận biểu hiện tăng creatinin gặp $2.3 \%$. Mặc dù muối platinum thế hê 3 như oxaliplatin ít độc tính với thân nên không khuyến cáo phải truyền nhiều dịch hoặc lợi tiểu vào ngày truyền oxaliplatin.

Nghiên cứu Phan Thị Hồng Đứctrên 158 bệnh nhân UTĐT giai đoạn III điều trị phác đồ FOLFOX4 tác dụng thần kinh ngoai biên $92,8 \%$ có độ 3 chiếm $17,7 \%$, nôn và buồn nôn chiếm $73,7 \%$ trong đó độ 3-4 là $5,1 \%$, la chảy chiếm $23,6 \%$ trong đó độ $3-4$ là $5,6 \%$, giảm bach cầu $5,1 \%$ không có giảm độ $3-4$ và $8 \%$ giảm tiểu cầ?. Andre T. Và cộng sự (2004) nghiên cứu trên bệnh nhân UTĐT giai đoạn II, III hóa trị bố trợ phác đồ FOLFOX4, giảm bạch cầu hạt là $78,9 \%$ độ 3-4 là $4,1 \%$, sốt do giảm bach cầu $1,8 \%$, giảm tiểu cầu $77,4 \%$, nôn $73,7 \%$, tiêu chảy $56,3 \%$ trong đó tiêu chảy độ 3-4 là 10,8\%2. Tác giả Từ Thị Thanh Hương nghiên cứu trên bênh nhân UTĐT giai đoạn III phác đồ FOLFOX4 cho thấy tác dụng thần kinh ngoại biên $21,7 \%$, nôn và buồn nôn chiếm $70,8 \%$, ỉa chảy chiếm $1,9 \%$, hội chứng bàn tay bàn chân chiếm $54,7 \%$, giảm bạch câu $42,4 \%$ trong đó giảm độ 3-4 chiếm $6,6 \%$ và $28,2 \%$ giảm tiểu cầu. Tăng men gan và tăng creatinin chiếm tỉ lệ ít, thường ở mức độ nhệ". Kết quả này cũng tương tự như nghiên cứu của chúng tôi.

\section{KẾT LUẬN}

Hóa trị bổ trợ phác đồ FOLFOX4 trong ung thư biểu mô tuyển đại tràng giai đoan II, III có kết quả sống thêm cao. Trong đó tỉ lể sống thêm không bệnh 3 năm là $79,1 \%$ và thời gian sống thêm khổng bệnh trung bình là 66,1 tháng, tỉ lệ sống thêm toàn bộ 3 năm là $88,4 \%$ và thời gian sống thêm toàn bộ trung bình là 71,9 tháng.

Hóa trị phác đồ FOLFOX4 có độc tính chấp nhận được. Các độc tính thường ở mức độ $1-2$, chỉ có $14,0 \%$ độc tính ở độ 3-4. Độc tính nặng về huyết học như giảm bach cầu hạt độ 3-4 là $9,3 \%$, giảm bạch cầu có sốt là $1,6 \%$, ảnh hưởng đến chức năng gan và thận chủ yếu ở mức $1-2$ tương ứng là $30,2 \%$ và $2,3 \%$. Độc tính trên hê tiêu hóa, thần kinh, da niêm mạc chủ yếu ở mức độ nhẹ. Các triệu chứng này giảm dần khi kết thúc điều trị.

\section{TÀI LIÊU THAM KHẢO}

\section{WHO.Globocan2020-VietNam.}

https://gco.iarc.fr/today/data/factsheets/populatio ns/704-viet-nam-fact-sheets.pdf. Published 2020. Accessed August 27, 2021.

2. André $T$, Boni $C$, Navarro $M$, et al. Improved Overall Survival With Oxaliplatin, Fluorouracil, and 
Leucovorin As Adjuvant Treatment in Stage II or III Colon Cancer in the MOSAIC Trial. J Clin Oncol. 2009:27(19):3109-3116.

doi:10.1200/JCO.2008.20.6771

3. Võ Văn Kha. Đánh giá kết quả điều tri hóa chât bổ trợ phác đồ XELOX trong ung thư biểu mô tuyến đai tràng giai đoạn II, III. Luận án Tiến sỹ Y hoc, trường Đai hoc Y Hà Nôi, 2016.

4. Từ Thị Thanh Hương. Đánh giá kết quả hóa tri bổ trơ phác đồ FOLFOX4 trong ung thư biểu mô tuyến đại tràng giai đoan III. Luận án Tiến sỹ Y học, trường Đại học Y Hà Nội, 2019.
5. Tsai Y-J, Lin J-K, Chen W-S, et al. Adjuvant FOLFOX treatment for stage III colon cancer: how many cycles are enough? Springerplus. 2016; 5(1):1318. doi:10.1186/s40064-016-2976-9

6. Nguyê̂n Quang Thái. Nghiên cứu giá trị một số phương pháp çhẩn đoán và kết quả sống 5 năm sau điểu trị phấu thuật ung thư đai tràng. Luận án Tiến sỹ Y hoc, trường Đai hoc Y Hà Nôii, 2002.

7. Phan Thị Hồng Đức. Hóa trị hỗ trợ carcinoma đại tràng giai đoạn III với phác đồ FOLLFOX4. Tạp chí Ung thư học Việt Nam. 2013;4:239-250.

\section{ĐÁNH GIÁ KẾT QUẢ Xử TRÍ CÁC BIẾN CHỨNG VÀ DI CHỨNG CỦA PHẪU THUÂTT CẮT THANH QUẢN BẢO TỒN TRONG UNG THƯ THANH QUẢN}

\section{TÓM TẮT}

Mục tiêu nghiên cứu: Xác định tỉ lê và đánh giá kết quả xử trí các biến chứng và di chứng của phâu thuật cắt thanh quản bảo tồn trong ung thư thanh quản. Đối tượng và phương pháp nghiên cứu: nghiên cứu mố tả cắt ngang, 219 bệnh nhân được phâuu thuật cắt thanh quản bảo tồn do ung thư thanh quản, tại bệnh viện tai mũi họng trung ương từ tháng 10/2018 đển 9/2021. Kết quả: Tỷ lệ biến chứng là $17,4 \%$, di chứng là $6,8 \%$. Tỉ lệ biến chứng của từng phương pháp mở sụn giáp cắt dây thanh, cắt thanh quản bán phần ngang trên thanh môn, CHEP, Tucker lần lượt là $20,6 \%, 15,4 \%, 16,4 \%, 17,4 \%$. Tỉ lệ di chứng của từng phương pháp là $0,9 \%, 38,5 \%$, $14,5 \%, 6,8 \%$. Tỉ lê các biến chứng chảy máu $5 \%$, tràn khí 9,5\%, nhiễm trùng vết mổ $2,3 \%$, viêm phổi $4,1 \%$. Di chứng chỉ gặp hep thanh quán với tỉ lệ $6,8 \%$. Kết luận: Phấu thuật cắt thanh quản bảo tồn có tỉ lệ biến chứng và di chứng thấp. Các biến chứng và di chứng có thể xử lý được và đem lại kết quả tốt cho bệnh nhân.

Tư khóa: ung thư thanh quản, cắt thanh quản bảo tồn, biến chứng và di chứng.

\section{SUMMARY}

EVALUATE COMPLICATIONS AND SEQUELAE MANAGEMENT OUTCOME OF CONSERVATION LARYNGEAL SURGERY

Objective: To determinecomplications and sequalae rates postoperative of conservative laryngeal surgery for laryngeal cancer and evaluate results of management outcome. Methods: cross-sectional study of 219 patients underwent conservative laryngeal surgery in National ENT hospital from October 2018 to August 2021. Result: Complication

${ }^{1}$ Bệnh viện Hữu nghi đa khoa Nghệ An

${ }^{2}$ Trường đại họ y Hà Nội

Chịu trách nhiệm chính: Phan Thanh Hưng

Email: phanthanhhung159@gmail.com

Ngày nhận bài: 18.6 .2021

Ngày phản biện khoa học: 18.8.2021

Ngày duyệt bài: 24.8.2021
Phan Thanh Hưng1, Tống Xuân Thắng ${ }^{2}$

rate was $17.4 \%$ and sequela rate was $6,8 \%$, complication rate of cordectomy, supraglottic horizontal, Tuker, CHEP was $20.6 \%, 15.4 \%$, $16.4 \%$, $17.4 \%$ respectively. Sequela rate of cordectomy, supraglottis, Tucker, CHEP was 0,9\%, 38,5\%, 14.5\%, $6.8 \%$ sequentially. Rate of hemmorrhage was $5 \%$ emphysema was $9.5 \%$, wound infection was $2.3 \%$ and pneumomia was $4.1 \%$. Conclusion: the conservative laryngeal surgery has relatively low complication and sequela rates. Postoperative care and management of complication and sequela are important.

Keywords: laryngeal cancer,conservative laryngeal surgery, complication and sequela.

\section{I. ĐẶT VẤN ĐỀ}

Ung thư thanh quản chủ yếu xuất phát từ biểu mô dây thanh, vùng thượng thanh môn ít găp hơn, vùng hạ thanh môn chiếm dưới $1 \%{ }^{1}$. Bệnh liên quan với tình trạng hút thuốc lá và uống nhiều rươu. Điều trị ung thư thanh quản chủ yếu là phẩu thuật và xạ trị, mục tiêu của điều trị không chỉ giải quyết bệnh tích khối u mà còn phải bảo tồn được chức năng của thanh quản. Phẫu thuật hiện nay có hai phương pháp cơ bản là phẫu thuật cắt thanh quản toàn bộ và phẫu thuật bảo tồn thanh quản.

Phẫu thuật cắt thanh quản bảo tồn áp dụng với các tổn thương u còn khu trú giúp bảo vệ chức năng nói, thở theo đường tư nhiên, tránh cho bệnh nhân phải mở khí quản vĩnh viễn. Có nhiều phương pháp phẫu thuật bảo tồn thanh quản khác nhau, tùy theo vị trí khối u và giai đoạn của khối u, tình trạnh của người bệnh và thói quen của phẫu thuật viên, để lựa chọn phương pháp phẫu thuật thích hợp. Ngày nay cùng với sự phát triển của khoa học kỹ thuật, trang thiết bi, phẫu thuât bảo tồn thanh quản đã có nhiều tiến bộ. Tuy nhiên, vẫn không thể tránh khỏi các biến chứng và di chứng mắc phải sau 